\title{
Sublimidad y nihilismo en la cultura del Barroco
}

\section{(Sublimity and nihilism \\ in Baroque Culture)}

\author{
Bernat CASTANY PRADO
}

Recibido: 15 de febrero de 2012

Aceptado: 20 de noviembre de 2012

\section{Resumen}

Este trabajo estudia el concepto de "lo sublime" en la cultura barroca, con el objetivo de demostrar que, aunque no fue teorizado sistemáticamente hasta el siglo XVIII, este cobró durante el siglo XVII una centralidad y, sobre todo, un significado filosófico semejantes a los que se impondrían posteriormente y que, según veremos, está estrechamente ligado con el concepto de "nihilismo".

Palabras clave: Nihilismo, Nietzsche, Estética, Barroco, Kant, lo sublime.

\begin{abstract}
This paper explores the concept of "the sublime" in the baroque culture, aiming to demostrate that, although it wasn't sistematically theorized until the XVIIIth century, it already played a significant role during the XVIIth century and, above all, gained a philosophical meaning, similar to those imposed subsequently, and as we will see, that is closely related withthe concept of "nihilism".
\end{abstract}

Keywords: Nihilism, Nietzsche, Aesthetics, Barroc, Kant, The sublime. 
Ya los dioses no cuidan de nosotros. Para ellos nuestras muerte es la ofrenda admirable.

Tucídides

\section{Introducción}

El objetivo de este trabajo es analizar el concepto de lo sublime en la cultura barroca. Soy consciente de que hasta el siglo XVIII dicho concepto no recibió una teorización filosófica sistemática ni empezó a desplazar a lo bello como concepto central en la teoría y la práctica del arte occidental. ${ }^{1}$ Esto no impide, sin embargo, que, en época barroca, lo sublime hubiese empezado ya a cobrar una centralidad y, sobre todo, un significado filosófico semejantes a los que se impondrían posteriormente.

Que la obra de Nietzsche coincida, por así decirlo, con la hora del exitus divino, no excluye una larga agonía ontoteológica previa que se habría iniciado con el profundo corte que supuso el humanismo renacentista -que por estar aún en caliente quizás no pudo ser intuido con total plenitud- $\mathrm{y}$ al que seguirían una infección barroca, una cauterización cartesiana, una recaída pascaliana, una falsa mejoría ilustrada y una septicemia romántica; culminando todo ello en la eutanasia nietzscheana y en el largo proceso de descomposición nihilista que dura hasta nuestros días.

Aunque dicho proceso no se explicitase hasta finales del siglo XVIII y principios del XIX, no tiene sentido considerar que empezó en ese momento o que las expresiones anteriores al advenimiento de su conciencia son casualidades ingenuas de un arte anterior a la expulsión del paraíso de la confianza en la existencia de un significado trascendente.

Según afirma Wölfflin, en Principios del arte (1915), dicha crisis empieza ya en la época barroca. Por su parte, para Arnold Hauser, la relación entre la crisis decimonónica y el siglo XVII es tan estrecha que "las categorías wölfflinianas del Barroco" se le aparecen como "la aplicación de los conceptos del impresionismo al arte del siglo XVII", llegando, incluso, a considerar que "Wölfflin subestima la significación del subjetivismo en el Renacimiento."2

También Tzvetan Todorov, en El jardín imperfecto, concibe al humanista del Renacimiento como un Fausto que ha firmado un pacto con el diablo en virtud del cual ha de adquirir de forma una libertad que deberá pagar de forma progresiva. Las tres letras de la hipoteca humanista serían, según Todorov, renunciar "a Dios" o al sentido, renunciar "al prójimo" o a la comunidad y renunciar "a la propia alma" o al sujeto. Ciertamente, el vacío del espacio infinito y la soledad de los grandes

\footnotetext{
${ }^{1}$ La traducción que Boileau realizó del tratado Sobre lo sublime del Pseudo-Longino no tuvo apenas repercusión en este sentido.

2 Hauser (2005), pp. 593-594.
} 
desiertos que Burke, Kant y Schopenhauer consideraban epítomes de lo sublime son jardines bien cuidados al lado del vacío metafísico que se le va a revelar al hombre a medida que comprenda el verdadero significado de su emancipación.

Recordemos, por ejemplo, cómo, según Arnold Hauser, la nueva libertad colocaba al artista barroco "en un vacío de libertad en el que muchas veces estaba a punto de perderse", pues "no estaban en condiciones de entregarse sin más a un guía externo ni de abandonarse por completo al propio impulso interior", lo que los dejaba "indefensos frente al caos que amenazaba el orden del mundo individual." El desgarro fue tan grande, continúa Hauser, que desde ese día "aumentan de día en día, entre los artistas, el raro, el excéntrico, el psicópata"; y pone como ejemplos a Parmigiano, que acabará sus días melancólico, vagando por las calles con un aspecto exterior lamentable; a Pontorno, que padecerá depresiones desde su juventud y con los años se volverá cada vez más misántropo y arisco; a Rosso, que acabará suicidándose; al Greco, que pasa el día encerrado en una habitación con las cortinas echadas; y a Tasso, que morirá enloquecido por los escrúpulos religiosos. (535-536)

Durante los siglos XVI y XVII, la ruptura de ciertos límites, considerados hasta entonces divinos o naturales, habría supuesto un sentimiento mezclado de liberación y vértigo, que son, mutatis mutandis, las características que Burke, Kant y Schopenhauer atribuyen a lo sublime. Mientras en el Renacimiento habría pesado más la sensación de liberación, en el Barroco habría pesado más la de vértigo y pérdida de sentido. Así, el paso del Renacimiento al Barroco puede entenderse como el paso de la claustrofobia del sentido que sentía el hombre renacentista frente al mundo medieval, a la agorafobia de la libertad que sentirá el hombre barroco frente a un mundo infinito y desordenado, dejado de la mano de Dios. Como la paloma del segundo prólogo a la Crítica del juicio, de Kant, el Renacimiento había pensado que en el vacío volaría mejor. Será el Barroco el que comprenda que la resistencia del aire no es sólo un límite para el vuelo, sino también su condición de posibilidad. Pero algo se ha roto definitivamente y los parches cartesiano e ilustrado no van a aguantar mucho en su desesperado intento de ocultar la grieta que se ha abierto en el centro mismo del pensamiento filosófico occidental.

La palabra "sublime", de "sub" (bajo) y "limis" (límite, frontera o puerta) ${ }^{3}$, no sólo está directamente relacionada con el concepto de límite 4 , sino también con la

\footnotetext{
3 Corominas (1980,) p. 545.

4 Según el diccionario etimológico Ernout-Meillet, el término "sublimis" no tiene ninguna relación con el término "limen" (umbral) sino con el adjetivo "limus", que tendría el significado de "inclinado" y que significaría desde muy antiguo elevado o excelso. No importa si esto es cierto ya que nues-
} 
negación de límite, esto es, con la ilimitación o infinitud. 5 No debería parecernos extraño, pues, que dicho concepto cobrase relevancia en las épocas renacentista y, especialmente, barroca, que se caracterizan por experimentar un trágico proceso de disolución de toda una serie de límites (geográficos, cosmológicos, sociales, religiosos, filosóficos) que habían definido y ordenado el universo durante toda la Era Medieval6.

Un mundo cuyos límites se disuelven es un mundo que tiende a la ilimitación o infinitud; y un mundo infinito es un mundo que ha perdido tanto los límites o fines exteriores, convirtiéndose en una realidad inabarcable, inconcebible o inconmensurable, como los límites o fines interiores, transformándose en algo mezclado, indistinto y desordenado.

Ciertamente, ambos significados están estrechamente relacionados. Avancemos, a modo de ejemplo, cómo la infinitud externa del cosmos llevará a Giordano Bruno a afirmar su infinitud interna, esto es, la indistinción entre mundo sublunar y supralunar, la inexistencia de un punto central del universo o la negación de que Dios mantuviese una relación privilegiada con una u otra parte del universo.

Resulta, pues, esencial, para comprender lo sublime barroco, tener en cuenta los procesos de disolución de los límites geográficos, cosmológicos, sociales, religiosos y cognoscitivos de los que fue testigo. ${ }^{7} \mathrm{Mi}$ intención es mostrar que dichos procesos, que se iniciaron o maduraron a lo largo de los siglos XVI y XVII, están íntimamente relacionados con la crisis filosófica que comparten lo sublime barroco con lo sublime ilustrado (Burke, Kant), romántico (Schelling, Schopenhauer, Nietzsche) e, incluso, posmoderno (Lyotard).

En lo que respecta a los límites geográficos, baste señalar cómo el descubrimiento de América supuso la ruptura de la vieja concepción geográfica del mundo. Según explica Edmundo O’Gorman en La invención de América, la vieja concepción terrestre no sólo era limitada o finita exteriormente, pues la Ecumene, "nuestro mundo", se dividía en tres única partes habitables, Europa, África y Oriente, sino

tra vocación no es cometer la falacia etimologista, que afirma que en la etimología de las palabras se halla su verdadero significado, sin contar que lo que importa es que, si esta etimología fuese cierta, el significado que posteriormente habría adquirido este término -inabarcable, ilimitado, inconmensurable- es compatible con nuestra afirmación.

5 La bibliografía sobre el concepto de lo sublime es inabarcable. Es iluminadora la presentación que realiza Viñas (2007) al concepto de lo sublime en Longino (pp. 74-79), Burke (pp. 214-221) y Kant (pp. 234-249). Sobre lo sublime en Schopenhauer, véase Puleo (1991: pp. 63-67) y Rosset (1969). Sobre lo sublime en general, véase Carchia (1994), Aullón de Haro (2006) o González Moreno (2007). ${ }^{6}$ Resulta significativo que el primer testimonio moderno de esta palabra date de mediados del siglo XV y que su práctica artística se inicie a finales del siglo XVI, con algunos fragmentos de los Ensayos de Montaigne, El rey Lear de Shakespeare, La cena de las cenizas de Bruno o las últimas obras de Miguel Ángel; y culmine en el siglo XVII, en obras como los Pensamientos de Pascal, El criticón de Gracián o el Primero sueño de Sor Juana Inés de la Cruz.

7 Véase al respecto el fundacional estudio de Lovejoy (1945). 
también limitada o finita interiormente, pues todo rasgo geográfico conllevaba un significado alegórico de tipo religioso: el carácter tripartito de la Ecumene se relacionaba con el de la Trinidad, con los tres Reyes Magos como embajadores ecuménicos y con la forma de la cruz; la ciudad de Jerusalén se hallaba en el centro; en África vivían los hijos malditos de Noé.

Según O'Gorman, la incapacidad de Colón para romper con esta visión cerrada, esto es, finita, del mundo le llevó a no querer comprender que había descubierto un cuarto mundo. De algún modo, Colón fue el primer nihilista. Será Américo Vespucio quien descubra realmente el Nuevo Mundo, poniendo en marcha un proceso de desdibujamiento de los límites o fines, que también podríamos llamar sublimación o infinitización. Como dijimos, dicho proceso afecta tanto a los límites externos como a los límites internos.

En lo que respecta a los primeros, baste tener en cuenta que "la vieja partición tripartita se concibe como formando parte de una mera serie numérica que admite adiciones ad infinitum de cuantas otras "partes" pudieren aparecer". 8 En lo que respecta a los segundos, cómo no sólo la geografía va a perder progresivamente sus implicaciones religiosas, anunciando ya el espacio vacío del racionalismo que tanto angustiará a Pascal, sino también la antropología, que va a empezar a cuestionar nociones como el diluvio, el creacionismo o la cronología bíblica, para sustituirlas por la idea de un tiempo geológico y una generación natural y múltiple del hombre.

No menos importante, en el proceso de disolución de los límites "naturales", fue el relativismo provocado por el descubrimiento de nuevas culturas y que se hace patente en un texto como "De los caníbales" de Michel Montaigne, en el que se desdibujan los límites entre civilización y barbarie al afirmarse que los caníbales son menos salvajes que los europeos puesto que comen gente que ya ha muerto mientras que los europeos torturan a gente que está todavía viva9.

Esta infinitud será vivida por los primeros renacentistas como una liberación. El buen salvaje, el utopismo renacentista, el amor por la infinita diversidad del mundo, las implicaciones emancipadoras del impacto secularizador que tiene su descubrimiento en la geografía o la antropología... son diversos aspectos del confiado entusiasmo con el que el Renacimiento vive la disolución de todo límite geográfico y cultural. Sin embargo, el hombre Barroco no va a vivir como una liberación esa doble infinitud externa e interna. Así, Pascal se angustia al pensar en "¡Cuántos reinos nos ignoran!" y llega a afirmar que "La infinita inmensidad de espacios que ignoro y que me ignoran. 10 "

En lo que respecta a los límites cosmológicos, baste señalar que en el siglo XVI, los rasgos esenciales del cosmos que habían dominado, con pocas alteraciones, los

\footnotetext{
8 O'Gorman (1958), p. 80.

9 Montaigne, "De los caníbales" (2001).

10 Pascal (1954), p. 1113.
} 
últimos dos mil años, se le revelarán al hombre europeo como falsos. El cosmos no es finito, ni esférico, ni geocéntrico, ni geostático, ni organizado en esferas concéntricas, ni dividido entre dos regiones, supralunar y sublunar, la primera de las cuales sería la morada inmutable y eterna de la divinidad y la racionalidad, y la segunda, el anus mundi o faeces mundi, esto es, las antípodas de Dios, escenario del nacimiento y la corrupción.

Según describe Alexander Koyré en Del mundo cerrado al universo infinito (1999), a partir del De revolutionibus (1543) de Copérnico -que a pesar de haber cuestionado dos de los elementos centrales de este cosmos, el geocentrismo y el geoestatismo, dejará intocadas el resto de las características del antiguo cosmos aristotélico-ptolemaico, que seguirá siendo finito, esférico, único y jerarquizado ontológicamente-, poco a poco dichos rasgos, que le daban definición, se irán perdiendo para dar lugar a un cosmos infinito tanto interna como exteriormente. ${ }^{11}$

Recordemos, por ejemplo, cómo Giordano Bruno, en La cena de las cenizas, estira las consecuencias del heliocentrismo copernicano hasta límites insospechados, concluyendo que el universo es infinito, de modo que no tiene un punto central; que es continuo y homogéneo, de modo que ya no está formado por estratos ontológicamente diferentes (negará la existencia del éter, el quinto elemento) y jerárquicos, sino que todo él es naturaleza; y que está constituido por infinitos sistemas solares o "synodus ex mundis", posiblemente habitados, lo que cuestionaría la despreciativa preferencia de Dios hacia el ser humano.

Ciertamente, todo ello tiene unas consecuencias filosóficas importantes, ya que el hecho de que todo sea un continuo natural homogéneo, implica que no hay cielo ni infierno; que Dios no puede tener una vinculación preferencial con una determinada región del universo, sino que mantiene la misma relación de inmanencia, indiferencia, con todo el universo; que el hombre no está más lejos de dios donde está que si estuviese en cualquier otro lugar.

Sin embargo, mientras que Giordano Bruno vive esta revolución como una liberación, Kepler y Pascal ("El silencio de los espacios infinitos me aterra"12) sienten agorafobia ante el infinito bruneano y se aferran desesperadamente a la idea de un universo finito y jerarquizado ontológicamente, con una significación moral y religiosa y un cielo estrellado que les hable directamente.

En lo que respecta a los límites sociales, recordemos que el ascenso de la burguesía y la instauración de una economía monetaria y de mercado va a suponer la crisis de una sociedad estamental en la que los límites entre los diferentes sociales eran claros, fijos y estancos. El capital, cuya naturaleza, como dice Marx, es romper todos los límites e igualarlo todo en cuanto mercancía, va a posibilitar la ascensión social y va a subvertir el sistema estamental, que mantenía ordenada la sociedad, al

11 Véase también al respecto Whitehead (1925), Rojo (1960), Granada (1988, 2000) y Toulmin (2001). 12 Id., p. 1113. 
permitir la compra de títulos nobiliarios a personas que no eran nobles por nacimiento. A esto se refiere, precisamente, Quevedo en su letrilla "Poderoso caballero es don dinero", donde habla de la capacidad del dinero para violentar todo tipo de límites (comprar títulos, pactar matrimonios entre nobles empobrecidos y burgueses, sobornar a jueces, etc.), ilustrándonos acerca de la sensación de indefinición, indistinción $\mathrm{y}$, por lo tanto, desorden, que sentía la sociedad de aquel momento.

Nuevamente, el Renacimiento, que es una época asociada estrechamente con la ascensión de la burguesía, sintió este proceso de disolución de los límites sociales como una oportunidad de emancipación. Ciertamente, Tomás Moro y otros utopistas renacentistas rechazarán el dinero, al no ser capaces de ver la fuerza socialmente igualadora que éste empezaba a mostrar; pero eso no impide que su rechazo de los méritos de nacimiento y su defensa y afirmación del individuo no estén relacionados estrechamente con los valores de la burguesía ascendente.

El Barroco, en cambio, vivió esta indefinición social con la angustia del que ve deshacerse todos los lazos sociales. Para empezar, tal y como indica José Antonio Maravall, frente al incremento de movilidad social protagonizada por la burguesía, la monarquía, la nobleza y el clero buscaron una "restauración tradicional" que mantuviese o restaurase las barreras o límites que el "antiguo régimen" establecía entre estamentos ${ }^{13}$. Según Maravall, la cultura del barroco sería, en buena medida, la gran campaña de propaganda que buscaría restablecer la hegemonía social y cultural de un Ancien Régime que ya empezaba a ser cuestionado.

En lo que respecta a los límites religiosos, el Renacimiento se va a entusiasmar con la apuesta por recuperar un cristianismo primitivo, con la lucha contra la industria del miedo, que incluía el comercio con indulgencias y reliquias así como con la defensa del libre examen individual, que van a oponer al oscurantismo de la Iglesia y al monopolio interpretativo que ésta detentaba con respecto de las Escrituras.

Sin embargo, cuando a principios del siglo XVI se produzca la traumática ruptura de la unanimitas cristiana, y el fanatismo y la barbarie inunden Europa, se va a producir una progresiva pérdida de confianza en la religión cristiana como unidad que establece los límites frente a la barbarie exterior y la herejía interna.

Los límites externos del cristianismo se nos revelan totalmente desdibujados cuando Erasmo afirme en su Querella pacis (1517) que "los que llamamos turcos son en gran parte semicristianos, y quizá más próximos al verdadero cristianismo que la mayoría de nosotros." También se nos aparece disuelta la frontera externa del cristianismo cuando Montaigne afirme: "Comparad nuestras costumbres a las de un mahometano, a las de un pagano; siempre estáis por debajo de ellos. ${ }^{14 " ~ T a m p o c o ~ e l ~}$ cristianismo establecerá una frontera clara entre luz y oscuridad, entre civilización y barbarie, cuando Castellio afirme, en su De arte dubitandi (1562), que "la poste-

13 Maravall (1972), p. 24.

14 Montaigne, op. cit., II, xiii. 
ridad no podrá creer que, después de que ya se hubiera hecho la luz, hayamos tenido que vivir de nuevo en medio de tan densa oscuridad." 15

Sin embargo, la ruptura de la unanimitas cristiana no sólo supondrá una crisis de los límites externos de la religión, sino también de los internos, pues los humanistas tomarán conciencia progresivamente de las dificultades de armonizar la cultura grecolatina -el atomismo democriteano, el escepticismo pirrónico, la economía de los placeres epicúrea, la antropología cínica- y la religión cristiana.

Por si esto no fuera suficiente, la crisis de los límites religiosos externos e internos desencadenó una crisis todavía más profunda, una crisis escéptica o pirrónica que disolvería el límite de los límites: el que separa verdad y falsedad ${ }^{16}$. Tal y como estudia Popkin en La historia del escepticismo desde Erasmo hasta Spinoza, la ruptura de la unanimitas no fue sólo una querella religiosa sobre "la norma apropiada del conocimiento religioso, o lo que se llamó la regla de fe" 17 , ya que "el problema de encontrar un criterio de verdad, planteado inicialmente en las disputas teológicas, surgió después con relación al conocimiento natural, conduciendo a la crise pyrrhonienne de comienzos del siglo XVII. 18" Según Popkin, la caja de Pandora que Lutero abrió en Leipzig había de tener las consecuencias más trascendentales no sólo en teología sino en todo el ámbito intelectual del hombre" 19 , ya que cuestionar las normas de la Iglesia era cuestionar una certidumbre de milenios, "era como negar las reglas de la lógica" 20 , era, en fin, abrir el debate imposible de cerrar acerca del verdadero criterio de verdad.

La total disolución de la frontera entre verdad y mentira queda expresada en el “¿Qué sais-je?”, epicentro de la "Apología de Raimundo Sabunde”, de Montaigne, y que es expresión de un proyecto de búsqueda de un modo de pensar y de hablar que no afirme absolutamente nada. Sin embargo, Montaigne todavía vivirá este proceso de disolución de los límites cognoscitivos como una liberación o un aprendizaje, mientras que Descartes buscará acabar con la "plaga pirrónica" respondiendo al "¿qué sé yo?" con una afirmación, según él, incuestionable: el "cogito".

Sin embargo, como señala Lucien Goldmann en Le Dieu caché, a pesar de su intento restaurador, el racionalismo supuso "la supresión de dos conceptos estrechamente ligados, el de comunidad y el de universo, sustituidos por otros dos: el individuo razonable y el espacio infinito." 21 Sin contar que el Dios del racionalismo "el

\footnotetext{
15 Castellio (1953). Es también el epígrafe del libro de Zweig (2010), p. 5.

16 La crisis teológica coincidió, a su vez, con la reintroducción del escepticismo pirrónico en el pensamiento occidental gracias a las ediciones y traducciones de Henri Estienne y Gentian Hervet y, sobre todo, a la "Apología de Raimundo Sabunde", incluida en los Ensayos de Michel de Montaigne.

17 Popkin (1983), p. 22.

18 Id., p. 22.

19 Id., p. 25.

20 Id., p. 24.

21 Goldmann (1986), vol. I, p. 41.
} 
Dios cartesiano solamente interviene en el mecanismo racional del mundo para mantener su existencia una vez que lo ha creado arbitrariamente." 22

Pascal, por su parte, se verá tan oprimido por la infinitud cognoscitiva que dibuja Montaigne como por la infinitud espacial o temporal. En ese sentido, Harold Bloom acierta cuando dice, en El canon, que las Meditaciones de Pascal son una indigestión de los Ensayos de Montaigne y, añadimos nosotros, con Goldmann, del racionalismo cartesiano.

Ciertamente, también es sublime enfrentarse a este infinito cognoscitivo. La indistinción, la infinitud, entre verdad y mentira es tan o más atrayente, arrolladora y horrorosa como la de los espacios. No hay duda de que Descartes se acerca a "lo sublime" cuando en la segunda de sus Meditaciones metafisicas afirma que las dudas que él mismo se provocó en la meditación anterior lo han dejado "como si de pronto hubiese caído en unas aguas profundísimas, quédome tan sorprendido, que ni puedo afirmar los pies en el fondo ni nadar para mantenerme sobre la superficie."23 Esas aguas profundísimas, ¿no son mucho más vertiginosas y terribles que los espacios infinitos, tormentas y precipicios de los que hablan Burke y Kant?

Más aún, el arrinconamiento pirrónico que ejerce Descartes en el lector ¿no despierta en nosotros el instinto de conservación de la persona moral en medio de los acontecimientos, de que habla Burke? Al fin y al cabo, el criterio de verdad no es una cuestión puramente epistemológica. Estemos de acuerdo o no con su solución, al fin y al cabo, lo sublime sabe que toda resistencia ante lo sublime "sería enteramente vana24", Descartes nos oprime con la infinitud cognoscitiva con el objeto de extraer el diamante de nuestro carbón humano:

Arquímedes, para levantar la Tierra y transportarla a otro lugar, pedía solamente un punto de apoyo firme e inmóvil; también tendré yo derecho a concebir grandes esperanzas si tengo la fortuna de hallar sólo una cosa que sea cierta e indudable. ${ }^{25}$

También Pascal practicará lo sublime cognoscitivo en sus Pensamientos, Calderón en La vida es sueño, Gracián en El Criticón y Sor Juana Inés de la Cruz en el Primero sueño. Ciertamente, no puede ser casual que estos autores fuesen tan influyentes para uno de los grandes maestros de lo sublime moderno: Schopenhauer.

Resumiendo, el proceso de disolución de los límites en los ámbitos geográfico, cosmológico, social, religioso y gnoseológico va a provocar, en un primer momento, un estado de entusiasmo que va a ser seguido por un estado de melancolía.

\footnotetext{
22 Id., vol I, p. 44.

23 Descartes (2005), II.

${ }^{24}$ Kant citado en Bayer (1995), p. 212.

25 Descartes, op. cit., II.
} 
Melancolía, de "melas" (negro) y "kholé" (bilis), significaba, en los siglos XVI y XVII, lo que en nuestros días significa depresión. Podríamos decir, jugando con las etimologías, que el hombre que tiene límites está contento, de continere, contener, reprimir, mientras que el hombre que pierde sus límites de forma violenta o precipitada, se deprime, de "depressus", descomprimirse, perder la forma, por falta de fronteras que opriman su materia. No es improbable que el paso de uno a otro estadio se vea reflejado en las siguientes palabras de Hamlet, el melancólico por excelencia: "Él [el hombre] es la gloria del mundo, él es el gran modelo de otros seres. Y sin embargo, para mí, ¿por qué es sólo la quintaesencia del barro?’26

\section{II}

A continuación me gustaría estudiar hasta qué punto el arte barroco puede ser visto como un arte de lo sublime relacionado con la infinitización del mundo, tal y como la hemos entendido hasta ahora.

En primer lugar, cuatro de los cinco principios del arte barroco que Wölfflin define en Principios del arte (1915) pueden ser vistos como expresión de esta pérdida de límites exteriores e interiores. Así, la representación pictórica, frente a la lineal, supone, según Hauser, la "disolución de la forma plástica y lineal en algo movido, palpitante e inaprensible; el borrarse los límites y contornos para dar la impresión de lo ilimitado, inconmensurable e infinito"27. Valga como ejemplo el Juicio final, de Miguel Ángel, donde la armonía espacial de las composiciones renacentistas ha desaparecido en aras de "un espacio irreal, discontinuo, ni visto unitariamente ni construido con un patrón unitario" que ha renunciado totalmente "al efecto de perspectiva ilusionista." 28

Lo mismo sucede con el principio de profundidad, que sustituye el de superficialidad, que caracterizaría el arte renacentista, y que expresaría también la disolución de toda permanencia y delimitación. Según Hauser, la elección demasiado cercana del punto de vista y el empleo de primeros planos demasiado grandes hace que el espectador sienta "que la espacialidad es una forma de existencia dependiente de él y por él creada." 29

Lo mismo expresa el tercer principio, que afirma el carácter abierto y atectónico del arte barroco frente al carácter cerrado del clasicismo renacentista, donde "lo representado es un fenómeno limitado en sí mismo, cuyos elementos están todos enlazados entre sí y referidos unos a otros; en este aspecto nada parece ser super-

\footnotetext{
26 Shakespeare (2002), II, 2, vv. 305 y ss

27 Hauser, op. cit., vol. I, p. 595.

28 Id., vol. I, p. 522.

29 Id., vol. I, p. 595.
} 
fluo, ni tampoco faltar." 30 Las composiciones barrocas dan una sensación más incompleta e inconexa, causando en el espectador o en el lector la sensación de que "pueden ser continuadas por todas partes y que desbordan de sí mismas." 31

Finalmente, el principio barroco de oscuridad, causado por las violentas superposiciones, las perspectivas vertiginosas, el abandono de las líneas de orientación, la discontinuidad de la materia o el tratamiento desigual de los motivos, dificultan la comprensión de la representación, que se nos aparece como un desorden entremezclado, sin límites exteriores ni interiores que le den un significado preciso. Según Hauser, este deseo de oscuridad busca "despertar en el contemplador el sentimiento de inagotabilidad, incomprensibilidad, infinitud de la representación, tendencia que domina en todo el arte barroco." 32

Estos cuatro principios harían del arte barroco la expresión de una infinitud que podemos calificar de total, por suponer la negación tanto de los límites internos como de los externos. Así, la obra barroca no busca ya lo bello "como proporción serena y como totalidad íntegra33", ni entiende el arte en términos eudemonistas, sino que busca lo informe, lo inconmensurable, lo inaprehensible que provoca un "terror deleitoso", como dirá Burke en el siglo XVIII, relacionado con la desaparición de todas las limitaciones y la devolución del sujeto a sí mismo, que "tiene que afirmarse en su independencia y radicalismo frente al universo, tanto físico como social." 34

Existe, sin embargo, un quinto principio wölffliano que parece estar en contradicción con los otros cuatro. Es el principio barroco de unidad o integración, que se caracterizaría por el "afán de unidad" y que se expresa en "una acrecida voluntad de síntesis, y con ello un principio más estricto de composición." 35 Según Hauser, si en los cuatro primeros principios veíamos, "frente al arte clásico, el mismo impulso hacia lo suelto, lo ilimitado, lo caprichoso", en este aspecto, el Barroco se nos revela como "continuación del arte clásico del Renacimiento, no su antítesis", como supone Wölfflin. 36

En mi opinión, la voluntad de unidad del arte barroco no es una mera continuación del arte clásico renacentista, sino, antes bien, su exasperación desesperada. Por así decirlo, el hombre del Renacimiento gozaba de la infinita variedad del mundo sin angustiarse porque todavía poseía la ingenuidad de que todo era armonizable, explicable o dignificable, a la luz de un principio no siempre bien definido, mien-

\footnotetext{
30 Id., vol. I, p. 596.

31 Id., vol. I, p. 596.

32 Id., vol. I, 597.

33 Cassirer (1943), p. 359.

34 Id., p. 361.

35 Hauser, op. cit., vol. I, p. 597.

36 Id., vol. I, p. 597.
} 
tras que el hombre del Barroco ha perdido esa confianza y necesita desesperadamente el orden y la unidad.

Así, junto a la aplastante infinitud del mundo que expresan los cuatro primeros principios, la voluntad de unidad sería la respuesta del hombre barroco frente a lo sublime matemático y dinámico, el acto de auto-preservación moral del que hablan Burke y Kant, pues lo sublime manifiesta "el hecho de que no sucumbamos a lo enorme, sino que nos afirmemos frente a ello, y que nos conduzca a una elevación de todas nuestras fuerzas." 37

Esa misma voluntad de unidad es la que va a caracterizar la estética ilustrada. Como señala Cassirer en La filosofia de la Ilustración, Baumgarten, el fundador de la estética como disciplina filosófica autónoma, considerará dicha disciplina como la única posibilidad de reunificar lo particular y lo universal, esto es, de volver a reordenar y delimitar el mundo.

Pero como el hilo que unía las cuentas del collar del sentido se ha roto, Baumgarten no va a intentar superar el vértigo pascaliano del "hombre sin Dios", ubicado entre "dos infinitos" 38 , intentando resucitar a Dios, sino, antes bien, retirando su cadáver al tratar de sustituir el ideal de la "semejanza divina del conocimiento"39 (intellectus arquetipus), por un modelo humano, inmanente y sensible, del conocimiento (intellectus ectipus). Ciertamente, lo sublime no deja de ser una dramatización de las relaciones entre la limitada inteligencia humana y la infinitud del universo, que sólo podría ser aprehendida, por una hipotética inteligencia divina infinita.

Así, en el capítulo 38 del Libro de Job, Yahvé humilla a Job, que ha intentado comprender las razones por las que lo castigaba "sin razón", con una larguísima enumeración de imágenes sublimes que buscan aniquilar toda pretensión de teodicea por parte del ser humano.

Ciertamente, la Biblia hace trampas, ya que con la boca le prohíbe al hombre tratar de comprender las razones de Dios, mientras que con un guiño le asegura que éstas existen. En este sentido lo sublime religioso será siempre sublime "premoderno", puesto que el significado moderno de lo sublime sólo podrá surgir cuando los hombres pierdan la confianza en la existencia de una escondida razón divina. A partir de ese momento, lo sublime dejará de ser la dramatización de la revelación de un sentido inaccesible pero existente (el sol que deslumbrándonos nos informa de que existe), para empezar a convertirse en la revelación de una no revelación ("esa oscura claridad que desciende de las estrellas", como diría Racine), que es la característica esencial de la literatura moderna. En el centro de los Pensamientos ya notamos ese silencio, pues tiene que ser el mismo Pascal el que haga a la vez de Job y de

\footnotetext{
37 Cassirer, op. cit., 360.

38 Pascal, op. cit., pp. 1105-1113.

39 Cassirer, op. cit., p. 385.
} 
Yahvé, lamentándose no comprender la insondable sublimidad del universo infinito que él mismo se ha lanzado a la cara.

El proceso comunicante de desencantamiento del mundo y sublimación del arte va a ser irregular, guadianesco, lleno de recuperaciones y recaídas. En él, cada autor va a entonar "lo sublime" de un modo diferente: algunos de un modo desesperado, otros con la nostalgia del absoluto y otros con confianza en la fuerza inmanente del ser humano. Pero lo importante es que todos se enfrentan al mismo problema: la nueva condición infinita del mundo.

Tomemos, por ejemplo, el tropo de la enumeración retórica, que es, tal y como señala, ya a principios de nuestra era, Pseudo-Longino en Sobre lo sublime, una de las principales fuentes estilísticas de dicho sentimiento. El mismo Borges apuntará, en "Historia de la eternidad", que "es verosímil que en la insinuación de lo eterno - de la immediata et lucida fruitio rerum infinitarum- esté la causa del agrado especial que las enumeraciones procuran." 40

Así, en la Biblia, que es un libro en el que Dios se halla todavía en un estado de salud perfecta, dicho recurso estilístico expresa la diversidad de un mundo reconciliado en la divinidad. En los Ensayos de Montaigne, sin embargo, ese mismo tropo expresa más bien la diversidad de un mundo que halla su valor en la inmanencia, y que si todavía habla de Dios, parece tratarse más bien de una divinidad epicúrea, inmanente e indiferente a las oraciones y pecados de los hombres. En El rey Lear, en cambio, Shakespeare recurre a este recurso literario para dar cuenta del desorden de un mundo cuyo rey -presencia de Dios en la tierra- se ha retirado voluntariamente, dividiendo su reino en tres, para ser luego desposeído y humillado por sus propias hijas, que simbolizan una nueva visión del mundo para la que no hay más ley natural que la de la selva, esto es, la del interés personal del más fuerte. En Las meditaciones metafisicas y el Discurso del método, a su vez, el estilo apodíctico, hipnótico y falsamente tranquilizador de Descartes, ignora este recurso, lo que expresa, a contrario, una voluntad de negar la crisis y de reinstaurar el orden en el mundo. Por su parte, Pascal expresa, en Los pensamientos, la infinitud opresiva del espacio y del tiempo, que aniquila a un hombre radicalmente descentrado y desvalorizado. En la Enciclopedia, en cambio, se intenta domesticar el carácter desordenado de la realidad, reduciendo la enumeración caótica a mero orden alfabético. Finalmente, en Nietzsche, la enumeración caótica, cuyo dominio aprenderá también de Schopenhauer, expresa el carácter radicalmente inmanente de toda fuente de sentido.

Recordemos, a su vez, cómo Borges estudia, en "La esfera de Pascal", las diferentes entonaciones que a lo largo de la historia ha recibido la imagen que representa la infinitud -de Dios, del universo o de cualquier otra instancia considerada inconmensurable- como una esfera cuyo centro está en todas partes y la circunferencia en ninguna.

40 Borges, "Historia de la eternidad" en (1999), t. I, pág. 364. 
Según Borges, dicha imagen aparece ya en el mundo místico como expresión del carácter absoluto e incomprensible de un Dios que se siente como garantía invisible del orden visible del mundo. En 1584, en De la causa, principio de uno, Giordano Bruno utilizará esa misma imagen para describir con exultación el espacio celeste infinito y descentrado nacido de la revolución copernicana y cuyo advenimiento había vivido como una liberación física y espiritual.

Sin embargo, como continúa Borges, "setenta años después, no quedaba un reflejo de ese fervor y los hombres se sintieron perdidos en el tiempo y en el espacio". Fue entonces cuando Pascal "sintió el peso incesante del mundo físico, sintió vértigo, miedo y soledad", lo que expresó diciendo, nuevamente, que "la naturaleza es una esfera infinita, cuyo centro está en todas partes y la circunferencia en ninguna." 41

Borges puntualiza que en el manuscrito inicial Pascal había caracterizado dicha esfera como "effroyable", esto es, espantosa ${ }^{42}$. En el fragmento 206 de sus Pensamientos -"El silencio eterno de estos espacios infinitos me causa horror"-, Pascal recupera este sentimiento, que surge del hecho de que "Dios no habla ya en el espacio de la ciencia racional, y ello porque para construirla el hombre ha tenido que renunciar a cualquier norma auténticamente ética."43

Cabría añadir, quizás, a esta secuencia, el concepto de eterno retorno, que Nietzsche recupera, a su vez, del estoicismo para imprimirle un nuevo acento y significado, dibuja una esfera temporal infinita cuyo centro, el presente, se halla en todas partes y su circunferencia, su final, en ninguna. De este modo, el vitalismo nietzscheano, expresado en la aceptación de la imagen del eterno retorno, supondría una superación del nihilismo pascaliano, expresado en la angustia y el vértigo que le provoca al autor de Las provinciales la imagen de la esfera infinita.

En todo caso, a nadie puede escapársele que en la esfera de Pascal nos encontramos con casi todos los componentes básicos que caracterizan lo sublime según Burke y Kant, pues remite a algo infinito o inconmensurable; es una fuente de placer estético que rebasa los límites del eudemonismo o "de la mera apetencia de felicidad, de la búsqueda de gozo y satisfacción en objetivos finitos" 44 ; y produce terror, pues es "effroyable".

El tono desesperado de los escritos de Pascal podría hacernos pensar que no vive lo sublime como "exaltación y liberación", pues, en su caso, no es expresión de "la íntima libertad del hombre frente a los objetos de la naturaleza y al poder del destino." 45 Cabe responder, sin embargo, que ese tono desesperado inunda sólo la primera parte, titulada significativamente "El hombre sin Dios", y no la segunda,

\footnotetext{
41 Id., p. 364, si bien la cita es de Pascal, Blaise, op. cit., p. 1105.

42 Borges, "La esfera de Pascal", en op. cit., t. I., p. 15.

43 Goldmann, op. cit., vol. I, p. 50.

44 Cassirer, op. cit., p. 361.

45 Id., p. 361.
} 
que, a pesar de intitularse "El hombre con Dios", no consigue apagar plenamente la sensación de terror metafísico que ha ido apoderándose del lector.

Por otra parte, esa sensación de exaltación y liberación que Burke y Kant asocian a lo sublime no es dichosa ni triunfante, sino dolorosa y humillante. La fuerza moral que surge del fondo de dicho sentimiento y que responde a un instinto de conservación, no de la persona sensible, sino de la persona moral, frente a un poder infinito (en el caso de lo sublime infinito) o bruto (en el caso de lo sublime matemático) ante el cual no tenemos por qué doblegarnos, si bien nos doblega irremediablemente, y sin perder la conciencia de la vanidad de nuestro esfuerzo. Así, el hombre concebido como caña pensante y la apuesta pascaliana, pueden ser interpretados como ese diamante moral que surge del carbón humano presionado por la infinitud.

Tanto la enumeración caótica como la imagen de la esfera infinita ilustran que existe una continuidad filosófica fundamental entre lo sublime barroco y las reflexiones estéticas que se inician al respecto con Burke (1750) y Kant (1790). La única diferencia es que, como señala Lucien Goldmann, en Le Dieu caché, el hecho de que Dios ya hubiese abandonado el mundo "todavía no había desplegado sus últimas consecuencias" por la sencilla razón de que "su ausencia aún la percibía únicamente una minoría ínfima de los intelectuales de la Europa occidental." 46 De Pascal a Kant, el universo es la habitación del hijo muerto que los padres se resisten a vaciar.

Cuando Nietzsche afirma en el fragmento 11[411] de sus Escritos póstumos que relata "la historia de los dos próximos siglos", debería haber añadido que la suya era también la historia de los dos últimos siglos. Puede resultar iluminador para comprender dicha continuidad, avanzar el inicio de la historia del nihilismo hasta el Renacimiento mismo. ${ }^{47}$

Recordemos que, para Nietzsche, el nihilismo, al que también llamará voluntad de nada, pesimismo, degeneración vital, muerte de dios o decadentismo, es una realidad profunda, equívoca y plural, de la que cabe distinguir, al menos, dos tipos. El primero de estos dos nihilismos es el implícito y, según explica Gonzalo Mayos, en su introducción a El nihilismo en los escritos póstumos, consiste en continuar negando la muerte de dios, cerrar los ojos a la realidad de los tiempos, negar ser nihilista e, incluso, afirmar que se reacciona contra el mismo, reivindicando viejos valores sin comprender que con ello no se provoca sino la profundización del proceso y el bloqueo de cualquier alternativa o salida.

\footnotetext{
46 Goldmann, op. cit., vol. I, p. 47.

47 Es inabarcable la bibliografía acerca del nihilismo, en general, y de la genealogía del nihilismo, en particular.Son fundamentales las obras de Savater (1986), Severino (1991), Heidegger (1994), Jünger (1994), Sánchez Meca (1995) o Vattimo (2004). Para una introducción general, véase Volpi (2007) o Herrero Senés (2009). Para las necesidades de nuestro argumento bastará la excelente síntesis realizada por Mayos (2001).
} 
El segundo tipo de nihilismo es el explícito, y consiste en ser consciente de que "dios ha muerto". Éste se divide, a su vez, en dos nihilismos en función del modo en como se reacciona a esta noticia: el explícito pasivo, que consiste en reconocer la "muerte de dios" y la situación nihilista actual con todo lo que implica, pero que renuncia a cualquier respuesta afirmativa y cae en la angustia, la desesperanza y la destrucción; y el explícito activo, que consiste en proyectarse creativamente sobre el vacío de la "muerte de Dios" mediante la construcción de nuevos valores, nuevas fábulas, nuevas máscaras y nuevas interpretaciones 48 .

Ciertamente, ninguno de estos tres nihilismos existe en estado puro, sino que todos ellos se mezclan o suceden en un mismo autor u obra según sople el viento de su espíritu y de su letra.

Así, Descartes oscilará del nihilismo pasivo de la primera parte de sus Meditaciones metafísicas, que lo arroja a las sublimes aguas profundas del escepticismo pirrónico, con el nihilismo activo, creador, de su cogito, del que seguramente Nietzsche afirmó en alguna parte de su obra lo mismo que afirmó del cristianismo en todas: que es un buen intento de generar una nueva fábula, pero que atenta demasiado contra la vida.

Por su parte, Pascal reaccionará contra el sublime nihilismo pasivo de la primera parte de sus Pensamientos ("L'homme sans Dieu”), con el nihilismo implícito, negador, de la segunda parte ("L'homme avec Dieu").

Asimismo, Shakespeare pasará de la total indigencia metafísica a la que es arrojado Lear, a la reacción desencantadamente realista de Edgar, que simbolizará la voie du milieu que pasa entre la Escila de una cosmovisión trascendentemente ordenada y jerarquizada del universo, que ya no puede sostenerse, y la Caribdis de una cosmovisión desprovista de todo valor y significado en la que la ley de la naturaleza ha sido sustituida por la ley de la selva.

No hay corte alguno entre estos autores, que practican lo sublime sin teorizarlo, y Burke y Kant, que lo teorizan sin practicarlo. Es el mismo argumento con diferentes personajes. El nihilismo pasivo de Burke es la fábula de la belleza y el activo de Kant la de que, en lo sublime, Dios finge no existir como prueba de amor supremo para posibilitar la más radical autonomía del hombre. En Kant "Dios no ha muerto" sino que "se hace el muerto" para obligarnos a ser seres humanos y no meras criaturas. Resulta, pues, que la belleza es la lápida con la que el vigilante de tumbas del Zaratustra vuelve a tapar el sepulcro vacío, mientras que lo sublime es el abismo que nos devuelve la mirada.

No es casual que Kant asocie, por un lado, la vía de lo bello con la teología, la teleología y la comedia, pues en ellas siempre se da una reconciliación "final", y no sólo en un sentido temporal, sino también metafísico; y, por el otro, la vía de lo

48 Mayos (2001), pp. 5-35. 
sublime a la teodicea, que es un tratar con la ausencia de Dios, y la tragedia. Tampoco lo es que Nietzsche tradujese el binomio bello-sublime en la tensión dionisiaco-apolíneo.

Y esto nos lleva a una última razón para considerar que lo sublime barroco es "moderno": la de que la tragedia, que es el género de lo sublime por excelencia, resurgiese en todo su esplendor, tras más de mil quinientos años de hibernación, en plena era barroca. Lo que vendría después, en todo caso, sería "la muerte de la tragedia", tal y como estudia George Steiner en su libro homónimo.

Así, la comedia, como la teología, la teleología y la belleza, considera que el desorden y los conflictos que abundan en la realidad son subsumibles o armonizables en algún tipo de explicación "final". Un conflicto no sería, en esencia, más que un malentendido, ya que siempre existirá una instancia superior en la que se resolverán las tensiones, dándole a cada parte lo que le corresponde. Dicha instancia superior puede recibir nombres diferentes (Dios, naturaleza, necesidad histórica, destino nacional, progreso) pero siempre posee el mismo poder para explicarlo y justificarlo todo, sin dejar resto alguno de incertidumbre, absurdo o irracionalidad.

Según George Steiner, un ejemplo de interpretación cómica o "bella" de la historia sería la que realiza el judeocristianismo al considerar que "tras la suma de los tiempos, no puede caber duda de que Dios es justo para con el hombre" y que "el orden del universo y de la condición humana es accesible a la razón." 49 El libro de Job, sería, pues, una obra cómica. La respuesta del mundo hebreo a la tragedia griega.

La tragedia, la teodicea trágica o lo sublime, considera, en cambio, que existe un resto irreductible de desorden, necesidad, sufrimiento y caos, al que el hombre jamás podrá acceder. Como señala Steiner, el personaje trágico "es destruido por fuerzas que no pueden ser entendidas del todo ni derrotadas por la prudencia racional." 50 En la tragedia, las causas del desastre no son temporales y el conflicto no puede ser resuelto con medios técnicos, diplomáticos o sociales. Por así decirlo, "leyes de divorcio más flexibles no podrían modificar el destino de Agamenón; la psiquiatría social no es respuesta para Edipo." 51 Más bien, al contrario, el sentimiento trágico "nos afirma que las esferas de la razón, el orden y la justicia son terriblemente limitadas" y que ningún esfuerzo humano, sea científico, técnico, intelectual o social podrá jamás extender sus dominios 52 .

Asimismo, a diferencia de los falsos conflictos de la comedia, siempre reductibles a meros malentendidos, los conflictos de la tragedia son verdaderos conflictos: irresolubles, eternos e irracionalizables. Por eso, según Hegel, para que exista "lo

\footnotetext{
49 Steiner (2001), p. 10.

50 Íd., p. 12

51 Íd., p. 12

52 Íd., p. 13
} 
trágico auténtico es menester que las dos potencias en lucha estén justificadas cada una por su parte, que sean éticas." 53

George Steiner distingue, por ejemplo, entre la caída de Jericó, que obedecería al esquema de la comedia, de la belleza, pues sería justa o racional al tratarse simplemente de un castigo divino, y la caída de Troya, que obedecería al esquema de la tragedia, de lo sublime, ya que habría sido causada por el juego absurdo de los odios humanos y la participación caprichosa y misteriosa del destino.

Del mismo modo, las guerras que aparecen en el Antiguo Testamento se nos revelarían cómicas o bellas, ya que existe un criterio suficiente para juzgarlas justas o injustas; mientras que las guerras del Peloponeso se nos aparecen como trágicas o sublimes, ya que en ellas se despliegan "oscuras fatalidades" y un profundo sentimiento de desconcierto e incapacidad de comprensión.

En este sentido, Descartes y sus vástagos deberían haber leído la carta de 1769 a sir Horace Mann, en la que Horace Walpole afirma que "el mundo es una comedia para los que piensan, y una tragedia para los que sienten" o aquel fragmento en el que Schopenhauer afirma que "la vida de cada hombre, vista de lejos y desde arriba, en su conjunto y en sus rasgos más salientes, nos presenta siempre un espectáculo trágico; pero si se recorre en detalle, tiene el carácter de una comedia." 54

\section{Referencias bibliográficas}

Aullón de Haro, P. (2006): La sublimidad y lo sublime, Madrid, Verbum.

BAYER, R. (1995): Historia de la estética, México, F.C.E.

Borges, J. L. (1999): Obras Completas, Emecé, Buenos Aires.

CARChIA, G. (1994): Retórica de lo sublime, Valencia, Tecnos.

CASsirer, E. (1943): Filosofia de la Ilustración, traducción de Eugenio Ímaz, México, F.C.E.

CAstellio, S. (1953): De l'art de douter et de croire, d'ignorer et de savoir, Genève, Editions Jeheber.

Corominas, J. (1980): Breve Diccionario Etimológico de la Lengua Castellana, Madrid, Gredos.

Descartes, R. (2005): Meditaciones metafísicas, traducción de Guillermo Graíño Ferrer, Madrid, Alianza.

Goldmann, L. (1986): El hombre y el absoluto, 2 vols., Barcelona, PlanetaAgostini.

GonzÁlez Moreno, B. (2007): Lo sublime, lo gótico y lo romántico: La experiencia estética en el Romanticismo inglés, Universidad de Castilla la Mancha.

53 Cit. en Moro, Campanella y Bacon (1995), p. 19.

54 Schopenhauer (1851). 
Granada, M. Á. (1988): Cosmología, religión y politica en el Renacimiento, Barcelona, Antropos.

GranADA, M. Á. (2000): El umbral de la modernidad, Barcelona, Herder.

HAuser, A. (2005): Historia social de la literatura y el arte, traducción de A. Tovar y F. P. Varas-Reyes, Barcelona, RBA.

Heidegger, M. (1994): Hacia la pregunta del ser, traducción de José Luis Molinuevo, Barcelona, Paidós.

HerRero SenÉs, J. (2009): El nihilismo. Disolución y proliferación en la tardomodernidad, Barcelona, Montesinos.

JÜNGER, E. (1994): Sobre la línea, traducción de José Luis Molinuevo, Barcelona, Paidós.

KoYré, A. (1999): Del mundo cerrado al universo infinito, traducción de Carlos Solís Santos, Madrid, Siglo XXI.

Lovejoy, A. O. (1945): La gran cadena del ser, traducción de Antonio Desmonts, Buenos Aires, Nueva Visión.

Maravall, J. A. (1972): Teatro y literatura en la sociedad barroca, Madrid, Seminarios y Ediciones S.A.

Mayos, G. (2001): "Presentación" a Friedrich Nietzsche, El nihilismo en los escritos póstumos, Barcelona, Península.

Mirandola, P. della (2002): De la dignidad del hombre, traducción de Pedro J. Quetglas, Barcelona, PPU.

Montaigne, M. de (2001): Ensayos, traducción de Dolores Picazo y Almudena Montojo, Madrid, Cátedra.

Moro, Campanella y Bacon (1995): Utopias del Renacimiento, México, F.C.E.

O’Gorman, E. (1958): La invención de América, México, F.C.E.

PASCAL, B. (1954): Oeuvres complètes, Paris, Gallimard.

Popkin, R. H. (1983): La historia del escepticismo desde Erasmo hasta Spinoza, México, F.C.E.

Puleo, A. H. (1991): Cómo leer a Schopenhauer, Barcelona, Júcar.

Rojo, R. (1960): Los fundamentos metafísicos de la ciencia moderna, Buenos Aires, Sudamericana.

Rosset, C. (1969): L'esthétique de Schopenhauer, Paris, Presses Universitaires de France.

SÁnchez Meca, D. (1995): El nihilismo, Madrid, Síntesis.

SAVATER, F. (1986): Nihilismo y acción, Madrid, Taurus.

Severino, E. (1991): Esencia del nihilismo, Madrid, Taurus.

SCHOPENHAUER, A. (1851): Parerga y paralipómena.

Shakespeare, W. (2002): Hamlet, traducción de Manuel Ángel Conejero, Madrid, Cátedra.

Steiner, G. (2001): La muerte de la tragedia, Barcelona, Azul. 
Todorov, T. (2008): El jardín imperfecto, Barcelona, Paidós.

Toulmin, S. (2001): Cosmópolis, Barcelona, Península.

Vattimo, G. (2004): Nihilismo y emancipación, Madrid, Trotta.

ViÑas PiQuer, D. (2007): Historia de la crítica literaria, Barcelona, Ariel.

VolPI, F. (2007): El nihilismo, Madrid, Siruela.

Whitehead, A. N. (1925): Science and the modern world, Nueva York, Macmillan Company.

ZweIg. S. (2010): Castellio contra Calvino, Barcelona, Acantilado.

Bernat Castany Prado

Universidad de Barcelona

bcastany@ub.edu 